\title{
ISLAM PATUNTUNG: TEMU-TENGKAR ISLAM DAN TRADISI LOKAL DI TANAH TOA KAJANG
}

\author{
Islam Patuntung: \\ The Point of Struggle Between Islam and Local Wisdom in Tana Toa Kajang
}

\author{
Syamsurijal \\ Balai Penelitian dan Pengembangan Agama Makassar \\ Jl.A.P.Pettarani No.72. Makassar. \\ Email : ijhalbatigol@gmail.com
}

Naskah diterima tanggal 25 April 2014. Naskah direvisi tanggal 29 September 2014. Naskah disetujui tanggal 7 Oktober 2014

\begin{abstract}
Abstrak
Lokalitas selama ini digambarkan sebagai daerah terpinggirkan dan tidak punya daya. Namun apa yang dilakukan komunitas lokal Tanah Toa Kajang, justru sebaliknya. Di tengah gempuran modernitas, Negara dan agama resmi, mereka tetap survive berjalan dengan tradisi lokal mereka. Di saat yang sama lokalitas yang mereka miliki justru dijadikan arena untuk bertarung, bernegosiasi, beradaptasi, bahkan sekali waktu meresistensi kebudayaan baru tersebut. Tulisan ini menggambarkan proses itu, dengan mengambil fokus pada pertemuan antara Islam dan tradisi lokal mereka. Pada perjumpaan Islam dan tradisi lokal Patuntung itulah potret titik temu dan titik tengkar tersebut terpampang jelas. Tulisan ini merupakan ringkasan dari penelitian yang dilakukan secara kualitatif dari kurung waktu 2005 sampai sekarang. Karena ringkasan dari sekian episode penelitian, mungkin tidak bisa menggambarkan secara utuh proses-proses pergulatan tersebut.
\end{abstract}

Kata kunci: lokalitas, resistensi, negoisasi, Islam lokal

\begin{abstract}
Local community has been long described as marginalized people and have no power. However, local community of Tana Toa Kajang South Sulawesi, shows the contrary. Amid the on slaught of modernity and "official" religion, they have survived to live with their own local traditions. At the same time, their locality is the point of struggle to negotiate, adapt, and sometimes to resist to the new culture. The article describes the process, focused on the encounter of Islam with their local tradition. In the Islam and local tradition encounter, the portrait of struggle is clearly displayed. Because this paper is a summary of the result of qualitative research conducted from 2005, it can not describe fully the struggle process.
\end{abstract}

Keywords: locality, resistance, negotiation, local Islam

\section{PENDAHULUAN}

A pa yang kita bayangkan ketika kita mengucapkan lokalitas? Daerah pinggiran, non-mainstream, lawan dari pusat, lawan dari universalitas, terbelakang dan anti modernitas. Mungkin kata itu segera yang akan muncul di benak kita. Inilah juga yang acap kali menjadi gambaran kaum terpelajar (Akib, 2003). Bahkan jika negara diposisikan sebagai pusat dan kemodernan sebagai yang universal, maka lokalitas ini adalah arena yang dianggap disubordiasi oleh Negara maupun modernitas. Konteks ini memunculkan gambar buram tentang lokalitas; kumuh, terbelakang sekaligus tak berdaya.

Namun pandangan lazim bahwa yang lokal adalah yang tersubordinasi, yang selalu kalah dan hanya menjadi objek semata dalam banyak kasus komunitas lokal di Indonesia, tidak sepenuhnya benar. Apa yang digambarkan para antropolog era tahun 70 -an yang menganggap bahwa modernitas dan kekuatan negara telah membuat yang lokal dengan eksistensinya tak berdaya lagi, menjadi patut kita pertanyakan kembali. Betul bahwa pada masa Orde Baru, pemerintah telah mengeluarkan berbagai kebijakan yang mengkonstruksi sedemikian rupa 
kebudayaan bangsa ini. Konstruksi itu memang adalah upaya untuk mematikan yang lokal atau menempatkannya semata barang pajangan yang artifisial. Hanya berguna atau dimunculkan jika sudah dikomodifikasi dalam bentuk parawisata atau souvenir jualan. Tapi semua hal itu tidak betulbetul mematikan yang lokal. Mereka senantiasa membangun relasi yang berimbang melalui proses-proses negoisasi, adaptasi, bahkan acapkali resistensi. Etnografi Anna Tsing yang memukau tentang Dayak Meratus dalam In The Realm of Diamond Queen: Marginality in an Out of Way Place setidaknya mulai menunjukkan bahwa bicara yang lokal, bukan semata bicara tentang orang-orang yang selalu kalah (Tsing, 1998).

Kenyataan ini menunjukkan bahwa sesungguhnya lokalitas bukanlah ruang yang diam atau satu letak geografis belaka. Bukan pula hubungan satu arah melulu. Demikianlah, maka jika anda berbicara tentang lokalitas ketika dihubungkan dengan pusat atau yang global tidaklah sematamata soal yang mendominasi dan tersubordinasi (Barker, 2000). Bukan pula soal kepasrahan yang lokal terhadap dominasi pusat, pengorbanan yang lokal demi Kepentingan Negara. Lokalitas adalah arena, tempat komunitas yang bermukim di atasnya bergerak, membuat makna baru, membaca ulang, dan ruang-ruang kreatifitas dan lokus negosiasi. Kata Anna Tsing: "An out of The Way place is, by definition, a place where the instability of political meanings is easy to see". (Lokasi terpencil atau komunitas lokal adalah tempat dimana ketidak stabilan makna politik mudah dilihat) (Tsing, 1998: 48).

Begitulah komunitas Tanah Toa Kajang ini ketika berhadapan dengan apa yang kita anggap pusat, resmi dan modern. Mereka bukanlah komunitas yang diam. Mereka tidak serta merta lebur dan menjadi tidak berdaya. Mereka membaca ulang, membagun definisi dan membuat makna menjadi tidak stabil. Ketika berhadapan dengan agama 'resmi', seperti Islam, ia tidak serta merta lebur begitu saja dengan Islam dan kehilangan lokalitas mereka. Berbagai ajaran Islam yang diajarkan kepada komunitas ini, dibaca ulang dan disesuaikan dengan konteks mereka sebagai komunitas lokal dengan berbagai kepercayaan dan ritual yang mereka sudah miliki sebelumnya.

Singkatnya lokalitas yang menjadi arena komunitas Tanah Toa Kajang adalah arena mimikris yaitu sebuah peniruan dari lokal terhadap pusat namun diiringi pemaknaan ulang bahkan pengejekan. Jika boleh meminjam apa yang dikatakan Bhaba, maka tindakan komunitas lokal dalam melakukan mimikri adalah: "Mimicry is thus the sign of a double articulation; a complex strategy of reform, regulation and discipline, which appropeiates the Other as it visualizes power" (Bhaba, 1997: 152).

Pengalaman masyarakat Kajang dalam bersiasat, bernegoisasi, berdialog dan kadangkadang meresistensi hal yang dianggap universal, resmi dan pusat inilah yang menjadi focus bahasan dalam tulisan ini, dengan menjadikan pergulatan Islam dengan kepercayaan Patuntung sebagai arenanya. Dari sini kita bisa belajar bahwa sesungguhnya pada yang lokalitas itulah mozaik kebudayaan disusun dari pertemuan dengan berbagai kebudayaan yang ada, sehingga tidak tepat mengatakan ada kebudayaan yang betul-betul asli tanpa berbaur dengan kebudayaan lain (Parekh, 2004: 47).

\section{METODOLOGI PENELITIAN}

Tulisan ini disarikan dari hasil penelitian etnografi dan pendampingan penulis selama ini di Komunitas Tanah Toa Kajang. Saya menyebutnya etnografi, karena dalam pengumpulan data tetap mengikuti aturan etnografi, seperti pengamatan dan wawancara (Spradley, 1997). Karena itu yang diteliti tidak diposisikan sebagai objek, tapi merupakan bagian dari penelitian atau subjek penelitian. Saya menganggap mereka sebagai kawan dan tempat belajar sekaligus melebur secara aktif dalam aktivitas mereka. Tentu saja penggalian dengan cara Geertz yaitu thin description dan thic description dilakukan (Geertz, 1973: 147), meski mungkin tidak bisa tergambar sempurna dalam tulisan singkat ini.

\section{PEMBAHASAN \\ Islam di Tengah Tanah Toa yang Dua Wajah}

Komunitas adat Tanah Toa Kajang selama ini lazim disebut dengan Kajang saja atau Kajang Le'leng (Kajang hitam). Padahal saat ini tidak semua daerah Kajang menjadi bagian dari daerah adat Tanah Toa. Bila diamati di petanya lebih seksama daerah adat yang oleh komunitas adat Tanah Toa Kajang disebut sebagai daerah kawasan atau ilalang bata, juga terkadang disebut sebagai Ilalang embayya atau rabbang seppang secara geografis dikonstruksi sedemikian rupa ke tempat yang agak terpencil dan dipinggirkan agak ke sudut. Komunitas ini ada yang menyebutnya bagian dari suku Makassar (Mattulada, 1985), namun bagi komunitas yang bersangkutan mereka lebih senang menyebut diri mereka dengan suku Konjo. Bahkan 
menurut mereka suku inilah yang pertama di Sulawesi, mendahului Bugis dan Makassar.

Komunitas ini sendiri berdiam di Desa Tana Toa Kecamatan Kajang Kabupaten Bulukumba. Namun tidak semua masyarakat yang berada di desa Tanah Toa Kajang menjadi bagian dari komunitas adat Tanah Toa Kajang yang masih konsisten menjalankan tradisi pasanga ri Kajang (Pesan yang turun di Tanah Toa Kajang). Kawasan yang ada dalam lingkup adat yang secara ketat menjalankan Pasanga kemudian disebut Ilalang Embaya (dalam pagar) dan daerah di luarnya disebut Ipantarang Embaya (di luar pagar). Dari istilah rabbang kemudian dikonsepsikan kawasan dalam adat sebagai rabang Seppang (kandang sempit), sementara kawasan di "luar" dikonsepsikan sebagai rabbang luara (kandang luas). Rabbang Seppangna Amma ini juga menjadi batas sejauh mana seorang Amma Toa boleh bepergian.

Komunitas Ilalang embayya selama ini dianggap berpegang teguh terhadap tradisi dan Ipantarang embayya dianggap komunitas adat Tanah Toa Kajang yang telah terbuka menerima perubahan yang datang dari luar. Maka bila di ilalang emabayya kita masih melihat masyarakat konsisten dalam beberapa ritual-ritual adat, dan berpakaian secara adat, sebaliknya di Ipantarang embayya dengan mudah kita temukana orang-orang yang tidak lagi berpakaian hitam-hitam. Demikian halnya bila di ilalang emabayya alat-alat tekhnologi belum menyentuh mereka, maka sebaliknya di luar atau di Ipantarang embayya kita dengan mudah menemukan kendaraan bermotor, televisi di tiap rumah penduduk, dan handphone dimiliki oleh hampir setiap orang.

Selama ini menurut yang berkembang di masyarakat, bagi komunitas adat Tanah Toa Kajang yang ingin menerima perubahan dan modernitas maka harus memilih tinggal di luar kawasan adat atau Ipantarang embayya. Sedangkan mereka yang masih bisa berpegang teguh terhadap nilai pasanga dan tidak merubah pola kehidupan mereka, maka tinggalnya di dalam kawasan adat (Ilalangembayya).

Sepintas hal ini memang memunculkan dua wajah di Tanah Toa Kajang. Satu wajah yang berpegang teguh pada tradisi, dan wajah yang lain adalah yang terbuka terhadap perubahan dan modernitas. Jika patokannya pada pembelahan semacam ini, maka kita akan melangkah pada kesimpulan selanjutnya. Komunitas adat Tanah Toa Kajang Ilalang embayya dalam kehidupan seharihari diatur dengan hukum adat yang bersumber pada Pasanga ri Kajang, sementara yang Ipantarang embayya diatur dengan hukum-hukum Negara dan hukum Islam (agama yang mereka anut).

Betulkah demikian?. Tentu saja tidaklah sesederhana itu. Pembagian dua tempat, tidak berarti pula otomatis sistem kemasyarakatan komunitas ini bisa dibagi dua secara hitam putih. Orangorang di dua tempat ini, meski ada pembagaian semacam itu, tetap bersilang tindih dalam soal sistem kemasyarakatan dan tata kehidupan mereka. Di Ipantarang embayya pengaturan kehidupan masyarakat tidak hanya berpatokan pada hukumhukum positif (konvensional) dan hukum agama, tapi juga dalam beberapa hal masih tetap ikut pada aturan adat. Sebaliknya di Ilalang embayya, meski mereka berpegang teguh pada hukum adat, tapi dalam beberapa hal mengapresiasi modernitas dan agama (Islam). Keberadaan masyarakat di Ipantarangembayya menjadi semacam penghubung dengan perubahan yang terjadi diluar komunitas adat Tanah Toa Kajang ini. Pada titik tertentu orang-orang di Ipantarang embayya bisa menjadi pendorong perubahan yang positif bagi komunitas di ilalang emabayya, tapi tak jarang pula menjadi perusak terhadap orang-orang di ilalang tersebut. Pada dua wajah geografis inilah yang pada akhirnya temu tengkar Islam dan tradisi lokal yang diwakili oleh Patuntung dengan mudah kita temukan.

Namun sebelum melangkah ke sana ada baiknya kita melihat sejenak bagaimana Islam masuk ke daerah ini dan peranannya dalam membelah wajah Tanah Toa Kajang menjadi dua.

Bila merujuk penjelasan Amma Toa, dulunya tak ada pembagian ilalang dan Ipantarang embayya. Yang ada seluruh daerah Kajang adalah bagian dari kawasan adat. Bahkan saat itu, masa kerajaan Gowa, diperkirakan sebelum datangnya Islam ke daerah ini, daerah adat itu meliputi sampai ke Herlang hingga Ara, bahkan sampai ke daerah Kindang. Hal ini bisa dilihat dari adanya kesamaan ritual dan tradisi di beberapa tempat tadi dengan tradisi dan ritual di Tanah Toa Kajang (Wawancara Amma Toa Puto Palasa, 2007)

Pada masa itu, yaitu masa kerajaan Gowa, Amma Toa juga tidak dibatasi oleh aturan adat, dimana Ia hanya bisa berada didalam kawasan Ilalang embayya. Amma Toa acap kali menyambangi Raja atau Sombayya di Gowa. Tak jarang pula Amma Toa memimpin upacara adat di Gowa. Dalam salah satu ungkapan Pasangan di sebutkan Na Passiallo Gowa Na Kajang, I Amma (Amma Toa Hanya menjalani sehari saja dari Kajang ke Gowa).

Lalu siapa yang mengkonstruksi pembagian geografis Tanah Toa ini ? Terkait dengan soal ini ada 
dua versi, satu cerita mengatakan orang luar Kajang yang membentuknya yang lainnya mengatakan bahwa ini adalah kesepakatan Amma Toa dengan kalangan yang berasal dari luar Kajang, meskipun pada akhirnya kesepakatan itu muncul secara terpaksa dari pihak Tanah Toa.

Persoalan ini sedikit pelik, soalnya tak banyak kalau tidak mau dikatakan tidak ada literatur yang cukup jelas menceritakan proses konstruksi batasanbatasan wilayah. Namun sedikit keterangan dari tokoh adat menyatakan bahwa proses ini dimulai saat masuknya Islam (Aminah, 1989: 5). Ini terkait dengan islamisasi di satu sisi dan keinginan dari komunitas ini untuk mempertahankan keyakinan Patuntung yang sejak dari dulu mereka pegangi pada sisi yang lain. Benturan antara islamisasi dan keinginan mempertahankan keyakinan bagi komunitas adat Tanah Toa Kajang mengharuskan adanya reposisi dan relokasi.

Dalam berbagai literatur dijelaskan bahwa proses islamisasi di daerah sekitar Kajang dimulai ketika Abdul Khatib Bungsu yang kemudian bergelar dengan Datuk ri Tiro, meyebarkan Islam di sekitar Tiro, sekitar abad ke-16 (Katu, 2000). Di Kajang sendiri proses penerimaan Islam tidaklah serta-merta, apalagi di daerah Kajang memiliki sistem tradisi dan kepercayaan tersendiri, mereka memiliki Amma Toa sebagai Penghulu adat dan dianggap pemimpin spiritual yang tertinggi. Apalagi ada beberapa kebiasaan-kebiasaan masyarakat adat di kajang yang dilarang oleh agama Islam misalnya minum tuak dan makan babi. Namun tentu saja sebagai kerajaan yang berada dibawah naungan Gowa yang telah memeluk Islam, maka komunitas adat yang ada di Kajang inipun harus rela menerima agama baru tersebut (Cence, 1931: 2-3)

Penerimaan komunitas Amma Toa terhadap Islam ini tidaklah secara totalitas menerima apa yang dikandung dalam ajaran islam, di satu sisi mereka tetap ingin mempertahankan beberapa keyakinan mereka, seperti keyakinan akan pasanga ri Kajang, Amma Toa sebagai titisan Yang Maha Kuasa atau To rie Ara'na dan juga beberapa praktek-praktek ritual lainnya. Hal-hal seperti itu tentu saja tidak dibenarkan oleh Islam. Menurut cerita Galla Puto saat itu terjadi pertarungan antara Amma Toa dengan penganjur Islam yang datang (Datuk ri Tiro) pertarungan itu diawali dengan perdebatan persoalan hakiki, pertarungan yang berlangsung cukup lama ini akhirnya berlangsung imbang. Pertarungan kemudian dilanjtkan dengan adu kesaktian, inipun akhirnya berakhir imbang. Akhirnya saat itu antara Amma Toa, Karaeng
Kajang dan penganjur Islam yang datang (tidak jelas apakah Datuk ri Tiro yang dimaksudkan) sepakat untuk membagi wilayah Kajang ini. Ada daerah dimana tradisi Pasanga yang berlaku yang dikemudian hari dikenal sebagai Tanah Toa dan ada daerah dimana ajaran Islamlah yang berlaku. Datuk ri Tiro menerima hal ini, karena pada prinsipnya apa yang dilakukan oleh masyarakat adat di Kajang tentang proses ritual dan keyakinan ada kemiripan dalam Islam.

Sejak saat itulah wajah Komunitas Tanah Toa Kajang menjadi dua, sekaligus saat itu pula Islam diterima di daerah ini.

\section{Temu-Tengkar Islam dan Tradisi Patuntung di Tanah Toa Kajang}

Malam itu suasana kawasan adat (ilalang embayya)yang biasanya sunyi senyap, tampakramai. Orang-oarang berdatangan dari berbagai penjuru sambil membawa makanan. Di tempat pelaksanaan acara nampak beberapa lampu pelleng (semacam pelita yang dibuat dari satu jenis tumbuh-tumbuhan yang bernama pelleng) dipasang, Suasana dirumah itu nampak terang dan mulai ramai didatangi oleh orang. Sesekali gendang dipukul untuk memberi tanda kepada yang lain bahwa sedang ada ajjaga (pesta atau keramaian) di tempat tersebut. Malam itu memang diadakan pajagaan (pesta) oleh salah satu masyarakat adat Tanah Toa Kajang

Selepas magrib, beberapa penghulu adat tampak sudah berdatangan, mereka duduk di tempat yang sudah disiapkan. Kepala dusun benteng dan wakil amma Toa juga sudah datang. Saya sendiri dipersilahkan duduk disamping wakil Amma Toa. Disebelah saya duduk Tamrin (yang mendampingi saya selama dilapangan). Ia lalu membisikkan bahwa sekarang ini saya lagi duduk secara adat (accidong ada'). Setelah semua duduk pada tempatnya gendang mulai ditabuh, beberapa orang mulai melantungkan kelong Pajaga, (lagu untuk pesta). diiringi dengan bunyi gendang. Makanan mulai disajikan kepada para pemangku adat, ini diistilahkan dengan attoana ada'. Masingmasing dihidangkan satu dulan makanan dihadapan para pemangku adat, termasuk dihadapan saya. Juga dihidangkan Tuak Pahit sebagai minumannya. Salah seorang dari yang punya hajatan mebisiki saya, apakah saya bisa minum tuak seperti ini, saya mengangguk. Dia kemudian berkata bahwa acara adat seperti ini, apalagi kalau ada attoana ada" tidak absah apabila tidak disuguhkan Tuak.

Menjelang pertengahan malam, acara puncak mulai dilaksanakan. Anak kecil yang mau di kalomba 
dibangunkan dari tidurnya. Lalu ditengah malam dengan cuaca yang lumayan dingin, anak kecil dengan usia sekitar 2 tahun itu mulai dimandikan. Setelah itu lalu dipakaikan Tope (sarung hitam khas kajang) dan baju. Setelah acara ini selesai anak itu kemudian dibawah ke ruang tengah. Di sana telah tersaji beberapa makanan. Anak kecil ini kemudian dikalungi dengan kampalo (sejenis makanan dari bersa ketan yang dibungkus dengan daun kelapa). Setelah itu beberapa orang kemudian massolo yaitu memberikan sumbangan uang yang nantinya, pada acara yang diadakan oleh yang menyumbang pihak yang punya hajatan saat ini akan menyumbangkan pula uangnya.

Acara ditutup dengan permohonan doa dari Sanro :

Oh To Rie Akra'na kisarea mae kasalamakkang
Kasalamakang mange ri ana cucungku
Kasalamakkang mange ri tau tabba
Nabi Muhammad ri Tompo,na Ulungku...
barakka....barakka....barakka....Kun fayakun
(Oh To Rie Akra'na (Tuhan Yang Maha
Berkehendak) berikanlah kami keselamatan
Keselamatan bagianak cucu kami
Keselamatan bagi orang banyak
Nabi Muhammad diatas kepalaku semoga
berberkat (diucapkan tiga kali). Kun
Fayakun....!)

Inilah salah satu acara ritual adat akkalomba yang acap kali dilakukan oleh masyarakat tanah Toa Kajang yang berada di kabupaten Bulukumba ini. Acara ini biasanya dilakukan untuk bayi atau untuk anak-anak kecil yang ada didaerah ini agar terhindar dari penyakit. Inilah salah satu tradisi masyarakat Tanah Toa Kajang yang merupakan bagian dari keyakinan Patuntung yang ada dimasyarakat tersebut. Namun dalam praktiknya kini tradisi itu sudah berbaur dan kawin mawin dengan ajaran Islam, seperti yang tercermin dalam doa yang diucapkan oleh sanro tadi.

Mari kita bayangkan bagaimana To rie akra'na dan nabi Muhammad menjadi satu bagian dalam doa dan diucapkan dalam satu tarikan nafas. Inilah salah satu penggalan episode, di mana komunitas Tanah Toa Kajang ini menarik Islam bertemu dengan tradisi mereka. Tentu saja ini belum berakhir. Mari kita simak sebuah penceritaan berikut ini yang dituturkan dengan apik oleh Galla Puto (juru bicara Amma Toa, nama aslinya Puto Beceng).
Syahdan, kedatangan Datuk ri Tiro diketahui oleh Amma Toa, yang juga mengetahui bahwa Datuk ri Tiro ini datang membawa ajaran baru. Selain itu datuk ri Tiro juga diketahui memiliki ilmu yang tinggi. Lalu diundanglah Datuk ri Tiro untuk mengetahui apa maksud dan tujuannya, serta ajaran apa yang dibawanya. Akhirnya terjadilah perdebatan yang menarik antara keduanya seputar hakikat ketuhanan dan hakikat diri manusia. Dalam perdebatan yang sifatnya saling menjajal kedalaman pengetahuan itu diceritakan bahwa kemampuan keduanya berimbang. Setelah itu keduanya berusaha saling menjajal kesaktian masingmasing, yang kemudian juga berakhir imbang. Saat itu Datuk ri Tiro menyusun telur sampai tingginya melewati puncak rumah. Namun Datuk di Tiro dibuat terkesima karena Amma Toa sendiri menunjukkan kesaktiannya dengan mengambil telur itu mulai dari tengah, dan telur itu tetap tersusun, tidak ada yang jatuh. Pertarungan lalu dilanjutkan mereka berdua melompat kepelepah pohon kelapa, Datuk ri Tiro berdiri di atas pelepah itu, sedangkan Amma Toa berdiri dibawahnya dengan kepala menghadap ke tanah. Setelah pertarungan ini, mereka lalu ngasoh dibawah pohon kelapa tersebut. Amma Toa lalu menawarkan apakah Datuk ri tiro ingin minum air kelapa, Datuk ri tiro mengiyakan, lalu Amma Toa tanpa memanjat berhasil mendapatkan beberapa butir pohon kelapa, dia hanya menunjuk buah kelapa di pohonnya dan kelapa itu jatuh ketanah. Datuk ri Tiro tersenyum, lalu berkata: "kenapasusah-susah menjatuhkan kelapanya ketanah". Datuk ri Tiro lalu berdiri dan melambaikan tangannya kearah pohon kelapa, pohon kelapa itu tiba-tiba merunduk, lalu dengan gampang Datuk ri tiro memetik buah kelapa tersebut, kini Amma Toa yang dibuat tercengang.

Bagi komunitas Tanah Toa Kajang, seperti yang diungkapkan oleh Amma Toa cerita ini menunjukkan bahwa antara ajaran Islam dengan kepercayaan Patuntung sejak awal tidak ada yang saling menaklukkan. Kedua-duanya adalah samasama kebenaran dan karena itu mestinya yang terjadi adalah dialog dan saling mengisi antara keduanya. Dalam pasanga ri kajang (wahyu yang turun di Kajang) hal ini ditegaskan dengan ungkapan

Guru Sara' tala tappa ri patuntung tala assai kaguruanna, sanro tala tappa ri sara' tanga assai patuntunganna

Artinya : Seorang ahli syariat (Islam) tidak 
percaya kepada Patuntung tidak absah keahliannya, sedangkan Sanro (ahli patuntung) tidak percaya kepada Syariat (Islam) tidak sah ke-patuntungannya (Katu, 2003).

Atas dasar inilah komunitas Tanah Toa menerimna Islam sebagai agama resmi, namun dalam prakteknya tidak mesti sama dengan yang resmi itu sendiri. Mereka mendialogkan antara islam yang resmi dengan keyakinan Patuntung. Ini dapat kita lihat dalam peraktek keberagamaan mereka seperti shalat, haji dan soal keimanan terhadap wahyu Tuhan.

Dalam hal shalat misalnya, komunitas Tanah Toa ini juga mengenalnya, namun bagi mereka shalat tidak mesti seperti dalam tuntunan syariat Formal karena bagi mereka :

\section{Pakabajiki ateka'nu \\ Iyamintu agama \\ Naiyantu sembayangnga \\ Jaman-jamanji (gau'ji) \\ Pakabajiki gau'nu \\ Sara-sara makana'nu \\ Nanulilian latatabaya}

\section{Artinya:}

"Perbaikilah hatimu, karena itulah agama. Adapun sembahyang itu pekerjaan saja.

Perbaikilah tindak tandukmu, sopan santun dan kata-katamu, agar jauh dari segala cela." (Puto Beceng, 2003)

Dalam ungkapan lain di pasanga disebutkan : "Je'ne Talluka Sambajang Tamattappu" (Air wudhu yang tidak pernah batal dan sembahyang yang tdak pernah putus).

Pemaknaan tentang sembahyang bagi komunitas ini, semakin jelas, seperti yang tersurat dalam teks tadi. Bahwa yang namanya wudhu ataupun sembahyang tidaklah harus dibatasi dengan waktu atau sekedar aturan formal belaka, tetapi yang lebih penting adalah hikmah dari ritual itu dalam kehidupan sehari-hari. Keberadaan kita di dunia senantiasa diwarnai oleh makna-makna dari kesucian berwudhu dan ketawaddhu-an dari shalat kita.

Demikian juga dalam hal haji, mereka melaksanakan tetapi cara yang dilakukannya berbeda dengan cara dalam agama Islam. Ada dua cara mereka melakukan tradisi haji ini:

Pertama; Akkattere, yaitu tradisi potong rambut yang diwajibkan sekali bagi orang-orang dalam komunitas ini. Akkattere ini justru dimaknai sebagai hajinya orang komunitas Tanah Toa Kajang, dan bukan bagian dari aqiqah sebagaimana dalam ajaran Islam. Tentu saja yang penting dalam tradisi ini adalah bagaimana membangun relasi dan kehidupan sosial yang lebih baik di antara masyarakat Tanah Toa Kajang. Dan menurut Puto Beceng ini adalah salah satu hikmah yang paling subtansial dari haji.

Kedua; Tradisi haji yang dilaksanakan di Puncak gunung Bawakaraeng. Dalam tradisi ini diyakini bahwa proses pelaksanaan haji juga bisa dilaksanakan dengan naik di puncak Bawakaraeng, di sanalah dilaksanakan ritual haji sebagaimana orang lain yang melaksanakannya di Mekkah.

Soal keyakinan terhadap wahyu Tuhan, komunitas ini sama dengan Islam. Mereka percaya bahwa Tuhan menurunkan wahyu kepada para nabi-Nya yang kemudian menjadi Kitab suci para penganut ajaran-Nya. Mereka juga meyakini alQur'an sebagai kitab suci yang diturunkan bagi mereka sebagai umat Islam. Hanya saja bagi masyarakat kajang Qur'an bukanlah 30 juz, tetapi 40 juz. 10 juznya itu adalah Pasanga ri kajang. Bagi masyarakat kajang justru sepuluh juz yang terakhir inilah yaitu Pasanga ri kajang yang menempati tempat tertinggi dalam urutan wahyu, barulah kemudian al-Qur'an. Kenapa al-Quran menempati urutan kedua, jawabannya karena ia telah dituliskan dan terhimpun dalam teks. Bagi orang Kajang ketika Wahyu di bakukan dalam teks, maka ia sudah menjadi idiologis dan sarat kepentingan. Bukankan teks tertentu akan menunjuk pada kebudayaan, idiologi dan kepentingan tertentu pula. Ini tentunya berbeda dengan asumsi wahyu yang di anut kalangan Islam resmi (baca; Islam Arab). Dimana bagi Islam yang seperti ini wahyu adalah apa yang telah dibakukan dalam teks mushab Ustmani yang sekarang menjadi pegangan mereka. Diluar itu berarti bukan wahyu, meskipun sesungguhnya tanpa mereka sadari atau pura-pura tidak sadar diluar teks baku mushab Ustmani di kalangan Islam resmi (Arab)sendiri, terdapat teks lain.

Karena cara pemaknaan mereka seperti ini terhadap ajaran Islam, beberapa kalangan, khususnya dari Islam modernis sering menganggap cara-cara ibadah komunitas Tanah Toa Kajang berbau musyrik. Lalu ramai-ramailah para dai 
berdatangan kedaerah ini demi meng-“Islamkan” mereka secara sempurna. Yayasan UMI (Universitas Islam Indonesia) misalnya, sejak tahun 1995 telah menjadikan daerah ini sebagai daerah binaan khusus. Demikian halnya dengan pihak Muhammadiyyah, NU dan Depag, sejak tahun 70an, kelompok-kelompok agama ini giat melakukan Peng-"Islam"-an terhadap komunitas ini.

Bahkan Saat ini proses Islmisasi di daerah ini bukan lagi kewat gerakan kultural berupa dakwah atau pendidikan, tetapi sudah mengarah kepada pengaturan lewat Perda-perda yang di keluarkan oleh pemerintah daerah kabupaten Bulukumba. Perda tersebut antara lain: Perda no 03/2002, tentang larangan, pengawasan, penertiban dan penjualan minuman beralkohol, Perda no 02/2003 tentang pengelolaan zakat Profesi, infaq dan shadaqah, Perda no 05/2003 tentang berpakaian muslim dan muslimah, Perda no 06/2003. tentang pandai baca AlQur'an bagi siswa dan calon pengantin.

Meskipun demikian komunitas ini tidaklah takluk dengan proses islamisasi yang semakin kuat terhadap mereka. Mereka tetap kukuh menjalankan Islam yang mereka pahami selama ini dari hasil dialognya dengan tradisi yang mereka miliki. Sesekali nampak menyembul perlawanan-perlawan simbolik mereka terhadap purifikasi islam ini dalam dialog yang terkadang mereka lakukan dengan orang-orang dari luar. Seperti yang terjadi ketika kami berkunjung ke komunitas ini (Syamsurijal, 2005)

Saat itu setelah basa-basi sejenak dan menyantap suguhan khas tanah Toa, kamipun bercakap-cakap dengan Amma Toa. Dalam percakapan itu tiba-tiba saja Amma Toa melontarkan pertanyaan. "Kalian ini, anak-anakku tentu adalah orang-orang pintar, karena itu saya mau tanya, dalam sembahyang kalian sesungguhnya meyembah siapa, siapa yang anda bayangkan ketika meyebut nama Tuhan dalam shalat"?

Saya terperangah.... Saat itu kami semua diam, harus saya akui secara pribadi pertanyaan ini sangat sulit. "Pertanyaan ini pertanyaan hakikat, mirip pertanyaan Syekh Siti Jenar di hadapan sidang wali di jawa tempo dulu". Batinku saat itu .

Melihat kami terdiam, Amma Toa lalu melanjutkan bicaranya. "banyak di antara kita dalam sembahyang hanya membayangkan hurufhuruf dan nama Tuhan, padahal itu bukanlah Tuhan, dan bila itu dilakukan maka sesungguhnya kita sudah terjebak kearah kemusyrikan". "Kami sangat berhati-hati dalam hal itu, makanya kami disini sangat mementingkan tapapkkoro yaitu sikap perenungan dan penghayatan untuk lebih mengenal sang Khalik". Lanjut Amma Toa.

Pertanyaan Amma Toa di atas sungguh luar biasa, di tengah proses dakwah yang terus dilakukan kalangan tertentu terhadap mereka, karena dianggap Ke-islamannya belum sempurna, masih banyak takhayul dan musyrik, Amma Toa Justru mempertanyakan balik siapa sesungguhnya yang musyrik? Apakah komunitas tanah Toa yang begitu menjaga konstruk tentang tuhan, ataukah orang luar yang mengaggap Islamnya paling resmi?

\section{PENUTUP}

Secara keseluruhan, praktik yang dilakukan oleh komunitas Tanah Toa Kajang ini dianggap sebagai Islam Patuntung. Hal ini pernah dikemukakan oleh A.A. Cence dalam De Patoentoengs in Het van Kajang dalam edisi bahasa ingrisnya Patuntung in Mountain Of Kajang, (AA. Cence; 1931), Aminah dalam Nilai-nilai Luhur Budaya Spritual Masyarakat Amma Toa Kajang (Aminah,1989). G.F. de Jong dalam Ilalang Arenna (De Jong, 1996). Keyakinan semacam ini dianggap menyebar di beberapa tempat di Sulawesi Selatan mulai dari Gowa, Takalar, Bantaeang, Bulukumba, sebagian Sinjai dan sebagian Pangkep. Komunitas Tanah Toa Kajang dianggap sebagai pusat dari ajaran Patuntung ini. Istilah Patuntung dalam bahasa Konjo bermakna beberapa hal diantaranya: Belajar: yaitu orang yang menuntut ilmu kebatinan dan ilmu-ilmu yang berkaitan dengan religi untuk lebih mengenal Tuhan. Puncak atau ketinggian: sesuatu yang menjadi batas terakhir pencarian seseorang. Seseorang penganut patuntung akan berupaya menjcapai tingkatan ini. Mencari, yaitu satu kemauan yang keras dengan tekad bulat berupaya mendapatkan apa yang dicarinya, jadi bukan sekedar mencari, tetapi disana ada kemauan keras untuk mendapatkan apa yang dicari.

Islam Patuntung ini adalah sebuah terma untuk menunjukkan Islam khas lokal. Sebuah model dialog, negosiasi dan adatasi tradisi lokal terhadap apa yang dianggap universalisme. Islam Patuntung dapat pula dimaknai sebagai sebuah reistensi lokal terhadap agama yang dianggap universal. Ini juga menunjukkan bahwa yang lokal tidak betul-betul diam dalam berhadapan dengan kekuatan yang dianggap pusat dan universal.

Komunitas Tanah Toa pada akhirnya memang mengikuti ajaran Islam, melakukan peniruan dalam beberapa ritualnya namun disaat bersamaan 
mereka memunculkan pula sisi-sisi pengejekan, subversif dan penyempalan. Dalam hal ini bolelah kita baca dari pembacaan Homi Bhabha sebagai mimikri dan ambivalensi. Maka mengangkat cerita yang lokal dan subversif semacam ini bukanlah soal sekedar kembali kemasa lalu dan proyek romantisasi, tetapi ini seperti kata Partha Chatterje membangkitkan suara-suara lokal, yang subversif dan yang meyempal sebagai bagian dari resistensi terhadap yang pusat, yang baku dan diresmikan.

Namun selain itu, yang terpenting kita baca dalam konteks ini adalah keberhasilan komunitas ini menegoisasikan antara ajaran Patuntung dengan ajaran Islam yang datang kemudian. Dengan kreatifitas yang mereka miliki, mereka berhasil menerjemahkan Islam sesuai dengan lokalitas dimana mereka berada. Persis kata Amma Toa (pimpinan adat Tanah Toa):

\section{Naia agamaia nikalimbuki ri adaka \\ Artinya: Adapun agama, yang menyelimutinya adalah adat dan kebudayaan (Amma Toa: 2004)}

Hal ini sekaligus menunjukkan kepada kita bahwa agama ini sesungguhnya tidaklah tunggal, ia bisa berdialog dan membumi sesuai dengan tempatnya. Tinggal kini yang ditunggu adalah kreatifitas yang cerdas dari pemeluknya, bisakah mendialogkan Islam dengan lokalitas di mana mereka berada, atau malah menjadi komunitas yang kaku yang tidak bisa dengan luwes menuntun ajaran Islam berdialog dengan lokal dan zamannya. Komunitas Tanah Toa Kajang telah mengajarkan kita tentang itu.

\section{UCAPAN TERIMA KASIH}

Terima kasih kepada Amma Toa Puto Palasa yang tidak hanya memberikan data yang melimpah ruah, tapi juga seorang teman diskusi yang menyenangkan. Lebih dari itu dialah sang Penjaga Tradisi Patuntung ini, hingga tetap hidup dalam ruang dan waktu yang terus berubah. Demikian pula terima kasih pada Puto Beceng (Pemangku Adat), Galla Puto (Juru Bicara Tanah Toa Kajang), Abd. Salam (Kepala Desa Tanah Toa Kajang), dan Tamrin (Pemuda Tanah Toa kajang), yang tanpa kenal lelah menemani dan memperkenalkan komunitas Tanah Toa Kajang baik bumi dan langitnya.

\section{DAFTAR PUSTAKA}

Adhan, Syamsurijal. 2005. "Islam dan Patuntung di Tanah Toa Kajang; Pergulatan Tiada Akhir" dalam Hikmat Budiman (ed), Hak Minoritas; Dilema Multikulturalisme di Indonesia. Jakarta:Interseksi; Cet-I.

Akib, Yusuf. 2003. Potret Manusia Kajang Makassar: Pustaka Refleksi

Aminah, Siti, 1989. Nilai-nilai Luhur Budaya Spritual Masyarakat Amma Toa Kajang. Makassar: Kanwil Depdikbud.

Barker, Chris. 2000. Cultural Studies Theory and Practice .London: Sage Publication

Bhaba, Homi. 1997. "Of Mimicry and Man": The ambivalen of Colonial Discourse”, dalam Frederick Cooper dan Ann Laura Stoler (eds), Tensions of Empire: Colonial Cultures in a Bourgeois World. Barkeley: University of California Press

Cence, A.A. 1931. The Patuntungs in the Mountains of Kajang . Makassar: Naskah/Catatan laporan di KITLV dengan nomor daftar Cat.C.170.1931.

De Jong, Chris G.F. 1996. Ilalang Arenna. Jakarta: Gunung Mulia

Geertz, Clifford, 1973. The Interpretasion of Culture . New York: Basic Books Inc

Katu, Samiang. 2000. Pasang ri Kajang. Makassar: Pusat Pengkajian Islam dan Masyarakat PPIM IAIN Alauddin Makassar.

Mattulada.1985. Latoa: Suatu Lukisan Analitik Terhadap Antropologi Politik Orang Bugis Makassar: Hasanuddin Universty Press

Moleong, L.J. 2000. Metodologi Penelitian Kualitatif. Bandung: PT. Remaja Rosalakarya.

Parekh, Bikhu. 2000. Rethinking Multikulturalisme: Cultural Diversity and Political Theory. London: Macmilland Press.

Ridjal, Tadjoer. 2004. "Metode Bricolage dalam Penelitian Sosial” dalam Burhan Bungin (Ed), Metodologi Penelitian Kualitatif .Jakarta: Raja Grafindo

Spradley, James P.1997. Metode Etnografi .Yogyakarta: PT Tiara Wacana

Tsing, Anna Lowenhaupt. 1998. In The Realm of Diamond Queen: Marginality in an Out of Way Place. Princeton: Princeton University Press. diterjemahkan oleh Achmad Fedyani Saifuddin dengan judul Di Bawah Bayangbayang Ratu Intan: Proses Marjinalisasi Pada masyarakat Terasing . Jakarta: yayasan obor Indonesia. 